\section{ON THE BLISTER TREATMENT OF ACUTE RHEUMATISM.}

Bx HeRBERT DAVIES, M.D. Cantab., SENIOR PHYSICIAN TO THE LONDON HOSPITAL.

THF subject of the treatment of acute rheumatism is of such importance as to justify, I trust, my making a few observations upon the "Remarks on the Natural History of Rheumatic Fever," presented to the Royal Medical and Chirurgical Society, by Drs. Gull and Sutton, on Jan. 12th, 1869. In The LANCeT report of this communication I find the following statements:- "With regard to Dr. Herbert Davies' blister treatment, they remark that it very much relieves the pain and sufferings of the patients in some cases, but it does not appear to curtail the rheumatic process." And further: "It appears to us that there is not sufficient evidence to prove that any of the advocated systems of treatment have power to prevent the heart becoming diseased."

In contrast with these statements, I would beg to draw attention to the following passages from the "Clinical Histories" by Dr. Day, physician to the County Stafford Infirmary. "Although," he says, " so many especial remedies have been proposed for the treatment of acute rheumatism, and although without doubt they may each of them prove of service in properly selected cases, yet there is one that in my hands has never disappointed me in affording marked and almost immediate relief from those agonising articular pains which, with very few exceptions, are found to be present in acute rheumatic fever; and that remedy is the blistering method of Dr. Herbert Davies. Furthermore, I can fully endorse his opinion that where the remedy is made use of sufficiently early, and before any pericardial or endocardial symptoms are apparent, immunity from cardiac complications will be obtained. ......... In every case in which I have adopted it the relief from rheumatic pain has been beyond all doubt immediate, and for the most part permanent; and in no case have I seen supervention of pericardial or endocardial inflammation after the application of the blisters; so that, as far as I can judge, it seems to endue the patient with a sort of immunity from these complications." And lastly: "The effect upon the urine is very decided; for, however acid this secretion may have been before the blisters have been applied, it very speedily becomes after their application either neutral or alkaline, and this too in cases treated without the administration of any alkalies whatever." Again, in the Hospital Reports on the Treatment of Acute Rheumatism published in the British Medical Journal for Jan. 9th, 1869, it is stated that " at St. Thomas's Hospital Dr. Peacock has latterly employed blisters freely in such cases as admitted of their use; and provided several joints are affected, so that four, five, or six blisters can be applied at the same time, the beneficial effect is most striking; the local symptoms are very markedly and rapidly relieved, the constitutional disturbance is lessened, and the disease cut short; so that cardiac symptoms are prevented, or arrested if in process of development. He has not, except in very exceptional cases, relied wholly on the local treatment, but has added it to the constitutional measures which were previously in use, and the additional benefit gained is often most striking. It is applicable especially to the more intense cases of rheumatic fever, but is also very useful in those cases which are of such common occurrence where the disease develops itself in persons previously most reduced in health, and mor $s$ particularly in persons who have previously had the disease, and often with cardiac complication. ...... At the Westminster Hospital, Dr. Fincham has employed the treatment by blisters for some time, and he is satisfied that by this plan the relief produced is very great, and the duration of the malady shortened. He is in the habit, however, as a rule, of combining it with alkalies in full doses."

I might readily refer to many other members of the medical profession who have given their testimony to the value of the blister treatment in acute rheumatism; and those who have had no experience of this method I would take the liberty of referring to my communication on this subject contained in the London Hospital Reports for 1864 . I believe that the details of the cases there given in extenso will convince them that this plan of treatment not only rapidly and permanentlyremoves the agonising pain of the affection, but, when employed early, greatly diminishes the risk of the supervention of cardiac complications. It will be observed, from the tables published, that a fall of temperature in the axilla rapidly follows upon the establishment of a full discharge of serum from the close proximity of the inflamed joints; and that on the reduction of the temperature of the blood ensue a corresponding diminution in the force and frequency of the pulse, the return of sleep, and speedy convalescence of the patient. To secure this result, the plan recommended must be carried out in its full integrity-every joint inflamed must be treated in the manner proposed. And I can truly assert, after an experience in the use of this method during a period of four years, that $I$ have had no patients who have complained to me of the severity of the blister treatment. On the contrary, they have stated that their agonising pains commenced to disappear as soon as the effects of the blisters were established; and many, while expressing themselves grateful for the rapid relief obtained, have added that they would rather suffer the pain of forty blisters than undergo the terrible agony of a severe attack of acute rheumatism. It is evident, therefore, that my conclusions, founded upon practical experience, differ toto coelo from those of Drs. Gull and Sutton. I believe that well-marked, undoubted cases of rheumatic fever are under the control of medical art; and having learnt the value of the blister treatment in this affection, I feel that I should be acting unjustly to my patients in adopting the expectant plan which the authors of the "Remarks" are disposed to advocate.

Finsbury-square, Jan. 30th, 1869.

\section{d. altirror}

OF THE PRACTICE OF

\section{MEDICINE AND SURGERY IN THE}

\section{HOSPITALS OF LONDON.}

Nulla autem est alia pro certo noscendi via, nisi quamplurimas et morborum et dissectionum historias, tum aliorum, tum proprias eollectas habere, et inter se comparare.-Morgagri De Sed. et Caus. Morb., lib. iv. Procmiurn.

\section{HOSPITAL FOR CONSUMPTION, BROMPTON.}

CASE OF PHTHISIS, WITH DICROTOUS PULSE; SUDDEN DEATH.

(Under the care of Dr. PownLu.)

THe practical interest of the following case lies in the relation shown to exist between the circulatory condition indicated by the dicrotous pulse and the sudden death of the patient.

James B-_, aged forty-one, an assistant in a wine business, was admitted an out-patient on Feb. 5th, 1868. He was a tall, spare man, with a very nervous manner and anxious countenance. The pulse was quick, but regular.

History. - The patient had suffered from cough for one year, and from hoarseness for four months; but had been feeling decidedly ill for three weeks only. He had never had hæmoptysis. He complained of weakness, night sweats, some pain in the throat. Had led a rackety life, but had never had syphilis.

Physical signs. - On the right side dulness, with dry carernous respiration; tonsils large ; throat congested, with much mucous secretion and salivation.

He was treated with mineral acid and tincture of bark, and an astringent gargle.

Feb. 12th.-The patient's general condition much the same. He complained much of sleeplessness. Nervous manner, almost amounting to agitation, with much confusion and forgetfulness. Pulse rather quick, regular, dicrotous. There was no cardiac murmur. He was recommended to keep quiet, and some chlorodyne ordered at night. 